\begin{tabular}{|c|c|c|}
\hline & $\begin{array}{l}\text { European Association for the } \\
\text { Development of Renewable Energies, Environment } \\
\text { and Power Quality (EA4EPQ) }\end{array}$ & $\begin{array}{l}\text { International Conference on Renewable Energies and Power Quality } \\
\text { (ICREPQ'12) } \\
\text { Santiago de Compostela (Spain), 28th to 30th March, } 2012\end{array}$ \\
\hline
\end{tabular}

\title{
PREDICTION OF SPECIFIC FUEL CONSUMPTION IN TURBOCHARGED DIESEL ENGINES UNDER PARTIAL LOAD PERFORMANCE
}

\author{
L. Corredor, A. Escobar, I. Portnoy, E. Vélez \\ Department of Mechanical Engineering \\ Universidad del Norte \\ Barranquilla (Colombia) \\ Phone/Fax number: (57)(5) 3509509 Ext. 4272. E-mail: 1corredo@ uninorte.edu.co portoa@ uninorte.edu.co \\ iportnoy@uninorte.edu.co epareja@ uninorte.edu.co
}

\begin{abstract}
It is known that the performance of Diesel engine at partial load is different from the performance at full load, but engines manufacturers usually provide only the operation characteristics in the highest efficiency condition. In order to determine the Diesel engine performance at all operation condition an investigation has been conducted. The purpose is to develop a theoretical model based on the iso-consumption curve of the IVECO 8360.46.417 Diesel engine that allows predicting the refuse trucks engine consumption used in this work. With the curve and the information provided by the manufacturer the prediction of the specific consumption and performance of a refuse truck turbocharged engine fueled by Diesel was made using a two-variables regression with a third grade polynomial approximation. The result is a third grade polynomial that allows the specific consumption calculation depending on the torque and the engine speed.
\end{abstract}

\section{Key words}

Diesel Engine, Simulation, Specific fuel consumption, Turbocharged, Iso-consumption curve.

\section{Introduction}

So far, mostly researches have been focused on Diesel engine operation in highest efficiency conditions. Mostly, Diesel engine manufacturers only provide the operation conditions in the highest steady-state performance, at full load. However, most of the daily driving cycles include operation at partial loads. Consequently, the investigation of Diesel engine operations at partial loads has become important in order to know its behavior at real operating parameters. It is important to determine significant deviations from the highest steady-state performance in the most important operation parameters that are: specific consumption, efficiency and emissions. The purpose of the present work is a theoretical model development that allows Diesel engine operation conditions based on the IVECO 8360.46.417 iso-consumption curve and the data provided by the engine manufacturer.

\section{Problem Statement}

In the design and manufacturing process of an engine many tests are carried out in order to know the performance under partial and full load. However, Diesel engines manufacturers provide datasheets with few information about the engines performance. In some cases, they only specify the consumption in the operation condition with highest efficiency, which is under full load. In other cases, the manufacturers provide the specific consumption in three operation conditions which are Peak Torque, Government Speed and Maximum Power. Nevertheless, it is important to know the specific consumption and the performance under partial load for any engine. For this reason, the main purpose of this work is the development of a theoretical polynomial that allows the engine specific fuel calculation in function of the torque and the engine speed.

\section{Literature Review}

The performance of Diesel engines under partial loads has been widely studied, since the specific consumption at partial loads becomes higher than at full loads [1] [2]. The same occurs even when there is natural gas - Diesel dual operation [3].

Many efforts to predict the engines specific fuel consumption have been carried out. The fuel consumption for tractor engines at a particular load is obtained from ASAE D497, clause 3, which establishes a related equation. A most general equation for annual consumption is given by ASAE EP496.2 FEB03 [4]. These equations from ASAE have been tested ( $R$. Grisso) and it was concluded that they predict accurately the fuel consumption under partial loads [5].

There are also efforts to establish mathematical models in order to predict the specific fuel consumption as a function of the Diesel engine working parameters and, thus, to model the engine iso-consumption curves, which are generally similar shaped for Diesel engines [2]. S. 
Popescu, I. Dumitru, S. Boruz and Z. Kiernicki propose a second-degree polynomial to determine a Diesel engine specific fuel consumption dependant on an effective engine torque and engine speed as well as to elaborate the optimum working curve, which represents the function of engine torque dependant on speed engine for which specific engine consumption is minimum for each power level [6].

Radan Durković and Milanko Damjanović present a regression model [7] in the form of a third-degree polynomial in the function of working parameters, effective pressure and number of revolutions, that predicts accurately the specific fuel consumption for Diesel engines

\section{Methodology}

In the present work an outline of the procedure is given based on a regression model that has been presented in detail in previous publications [7]. As stated above, the main purpose of this work is the development of a theoretical polynomial that allows the specific fuel calculation in function of the torque and the engine speed. It is known that Diesel engines with similar characteristics have similar partial load performance [2]. For this reason, a specific fuel consumption curve corresponding to an engine whit similar characteristic to the refuse trucks ones was taken as a reference. To the development of the model, the IVECO 8360.46.417 iso-consumption curve was used (Agudelo John, Doctoral Thesis [8]) and it is shown below.

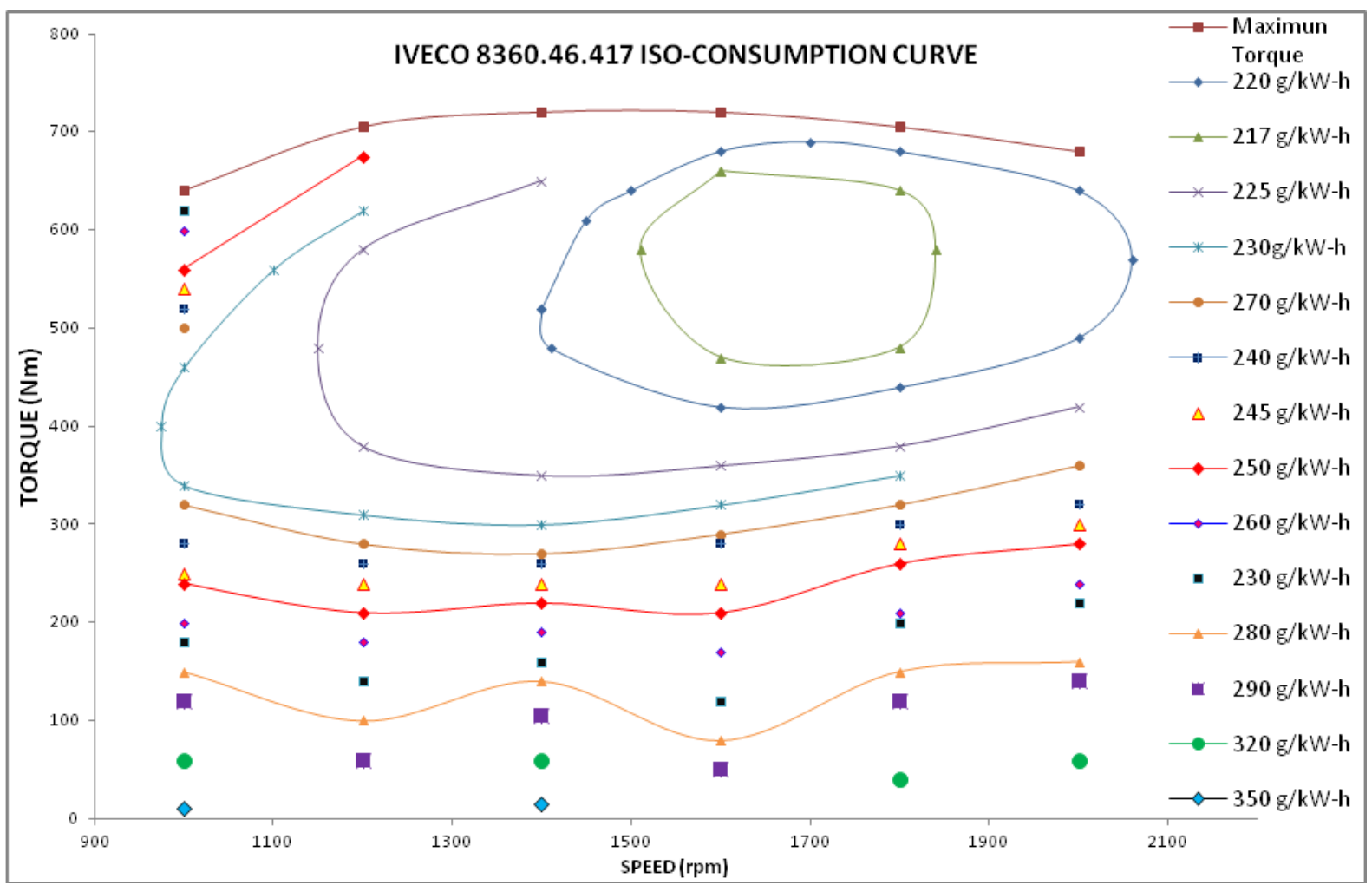

Fig. 1 - IVECO 8360.46.417 ISO-CONSUMPTION CURVE. Agudelo John, Doctoral Thesis [8]

The iso-consumption curve showed in Figure 1 can be made dimensionless in order to re scaled it. Knowing the operation conditions of the studied engine at three operation points given by the manufacturer its specific fuel consumption curve can be predicted. To this end, the dimensionless curve has to be scaled in order to force the three given operation points to fit the curve. Once the isoconsumption curve is predicted, the specific fuel consumption is related to the efficiency coefficient, this is why it is so important to know its behavior. The relationship among them is as follows:

$$
b_{\theta}=\frac{a 600}{B_{L} \eta_{M}}\left[\frac{\mathrm{kg}}{\mathrm{kW} W}\right]
$$

Where; $b_{e}$ is the specific fuel consumption, $\eta_{\mathrm{M}}$ is the efficiency coefficient and $H_{\mathrm{u}}\left[\frac{\mathrm{kJ}}{\mathrm{kg}}\right]$ is the fuel heating value. Generally, the specific fuel consumption is a nonlinear function of operation parameters, torque and engine speed, such as: $b_{e}=f(X)$. Where,

$$
X^{T}=\left[x_{1}, x_{2, \ldots,} x_{n}\right]
$$

Is the vector of operation parameters. Now it is linearized in the vicinity of the working parameters at the working point by Taylor series:

$$
\hat{b}_{a} \approx \sum_{j=0}^{k} \hat{a}_{j j} \cdot f_{i j}(x), i=1,2, \ldots, N
$$


By the application of the least square fit method:

$$
R=\min \sum_{i=1}^{W}\left(b_{e i}-\hat{b}_{i \mathrm{i}}\right) \text { and } \frac{\partial R}{\partial \hat{a}_{j}}=0,
$$

Where $j=0,1_{s, \ldots}, k$.

Then, a system of ordinary equations is obtained:

$$
F^{T}, F, \widehat{a}=F^{T}, \widehat{b}_{e}
$$

Where $f(X)$ defines the operation parameters at $N$ of known values $b_{\theta}$. And the vector of unknown coefficients of the regression equation is,

$$
\hat{\boldsymbol{a}}=\left[\begin{array}{llll}
\hat{a}_{1} & \hat{a}_{2} & \ldots & \hat{a}_{k}
\end{array}\right]^{T}
$$

Then, the equations system is solved:

$$
\widehat{a}=\left(F^{T}, F\right)^{-1}{ } F^{T} \cdot b_{e}
$$

The recommendation is to use a third degree polynomial form for the regression [7]. So the next regression model was chosen:

$$
\begin{aligned}
& \hat{b}_{g}=\hat{a}_{1}+\hat{a}_{2} T_{9}+\hat{a}_{a} n+\hat{a}_{4} T_{e} n+\hat{a}_{5} T_{g}^{2}+\hat{a}_{6} n^{2}+ \\
& \hat{a}_{7} T_{g} n^{2}+\hat{a}_{g} T_{g}+\hat{a}_{9} n^{a}+\hat{a}_{10} T_{g}^{2} n
\end{aligned}
$$

Where $T_{\oplus}$ is the torque, in this case in $H N . m, n$ is the speed in $R P M$, and $\hat{b}_{\theta}$ is the fuel consumption in $g / \mathrm{kWh}$.

\section{Results}

As stated above, the data points are from a heavy duty turbocharged Diesel engine commonly used in refuse trucks. The engine datasheet provided by the manufacturer specifies the maximum rating performance data at three operation points which are Governed Speed, Maximum Power and Peak Torque. The information is shown in the table below.

Table 1 - Maximum rating performance data

\begin{tabular}{|l|c|c|c|}
\cline { 2 - 4 } \multicolumn{1}{c|}{} & $\begin{array}{c}\text { Governed } \\
\text { Speed }\end{array}$ & $\begin{array}{c}\text { Maximum } \\
\text { Power }\end{array}$ & $\begin{array}{c}\text { Peak } \\
\text { Torque }\end{array}$ \\
\hline Engine Speed & $2200 \mathrm{RPM}$ & $2000 \mathrm{RPM}$ & $\begin{array}{c}1300 \\
\mathrm{RPM}\end{array}$ \\
\hline Output Power & $213 \mathrm{~kW}$ & $224 \mathrm{~kW}$ & $159 \mathrm{~kW}$ \\
\hline Torque & $922 \mathrm{~N}-\mathrm{m}$ & $1068 \mathrm{~N}-\mathrm{m}$ & $\begin{array}{c}1166 \mathrm{~N}- \\
\mathrm{m}\end{array}$ \\
\hline $\begin{array}{l}\text { Fuel } \\
\text { Consumption }\end{array}$ & $49.9 \mathrm{~kg} / \mathrm{h}$ & $49.9 \mathrm{~kg} / \mathrm{h}$ & $\begin{array}{c}35.2 \\
\mathrm{Kg} / \mathrm{h}\end{array}$ \\
\hline
\end{tabular}

With the data showed in Table 1, the dimensionless isoconsumption curve from the IVECO 8360.46.417 was re scaled. The predicted iso-consumption curve of the studied engine is shown below:

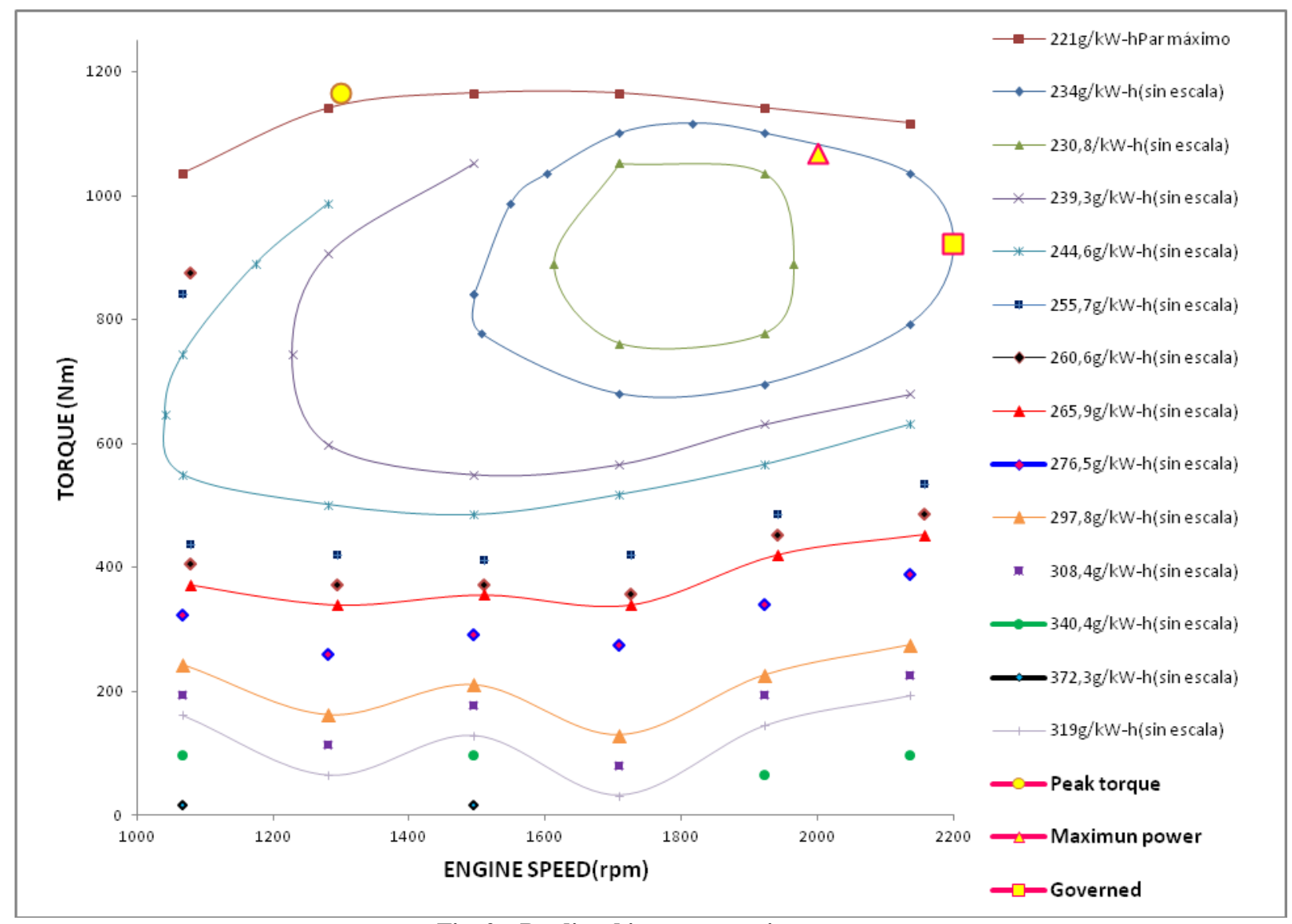

Fig. 2 - Predicted iso-consumption curve 
In this study, 118 values of consumption and working parameters were used to obtain the coefficients.
The regression coefficients are obtained and the resulting polynomial is as follows:

$\hat{b}_{e}=420,814546410482-51,5882970028774 T_{e}-0,0215840453514 n+0,0241860678868 T_{g} n+$ $3,2893682520578 T_{e}{ }^{2}-0,000064862217 n^{2}-0,0000083575876 T_{e} n^{2}-0,1107606818463 T_{e}{ }^{a}+$ $0,0000000308545 n^{a}+0,0000494527209 T_{e}^{2} n$

The specific fuel consumption curve is plotted and shown below:

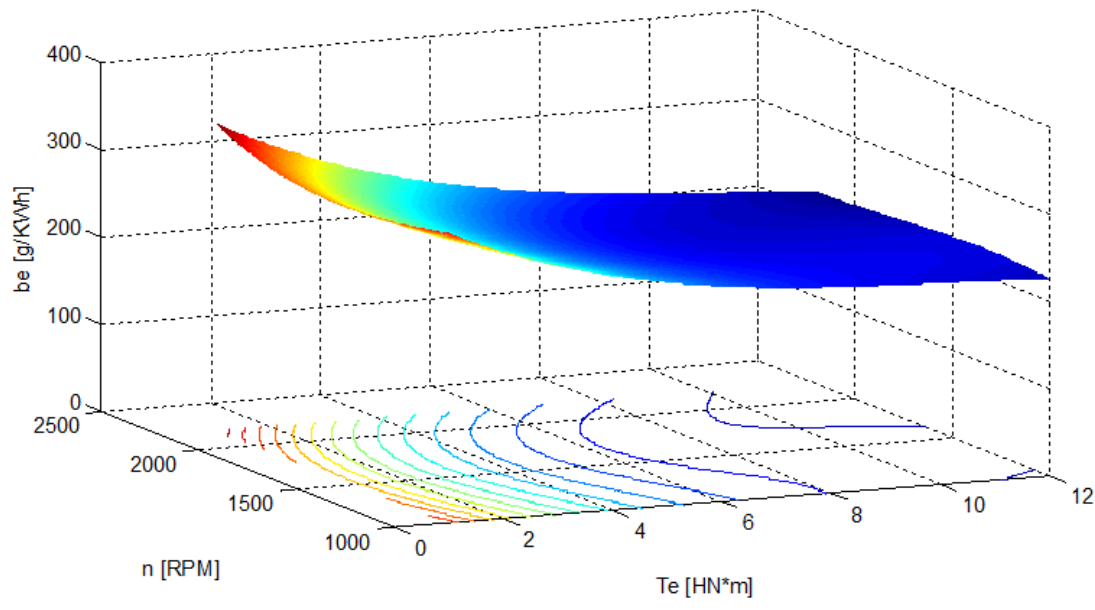

Fig. 3 - Predicted Specific fuel consumption curve

The efficiency curve can be also obtained:

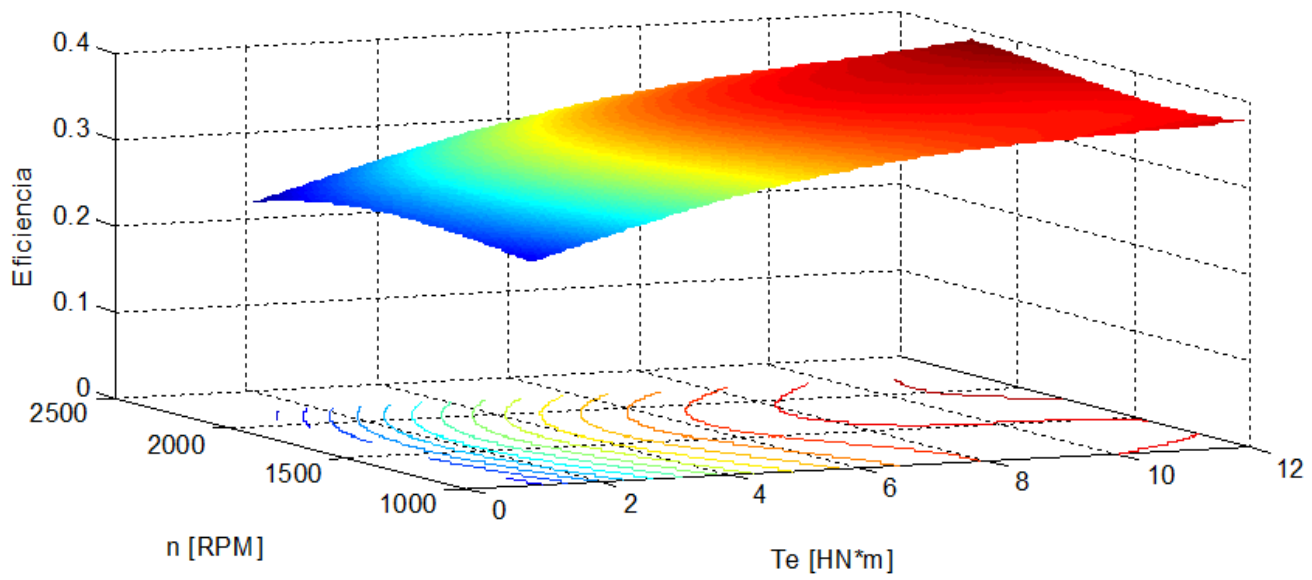

Fig. 4 - Predicted efficiency curve 
Table 2 - Obtained error for different load percentage related to the maximum load

\begin{tabular}{|c|c|}
\hline $\begin{array}{c}\text { LOAD } \\
\text { PERCENTAGE }\end{array}$ & ERROR $\left[\mathbb{g}_{\mathrm{kWh}}\right]$ \\
\hline $0-25$ & 9,452667702 \\
\hline $25-50$ & 3,542929544 \\
\hline $50-75$ & 6,852723984 \\
\hline $75-100$ & 6,852723984 \\
\hline
\end{tabular}

\section{Conclusions}

The proposed methodology allows predicting the specific consumption of a Diesel engine in any condition knowing little information about its performance, which, in some cases, is only about consumption in the operation condition with highest efficiency, under full load, or in other cases, in three operation conditions which are Peak Torque, Government Speed and Maximum Power Knowing the specific consumption at any condition lets us also predict the overall consumption in urban traffic conditions, which would be useful in preventive maintenance and also in a pre-feasibility study of massive transport means.

\section{Future Research}

Furthermore, a proposed methodology to predict the efficiency behavior in dual operation at different fuel substitution percentages with natural gas is presented. It is important to get information about the performance in some operation points and at different substitution percentages; this would be drawn as follows:

Table 3 - Future research parameters

\begin{tabular}{|c|c|c|c|}
\hline \multicolumn{2}{|c|}{$n_{\mathrm{i}}$} & $(\mathrm{rpm})$ & Scale Factor \\
\hline $\begin{array}{c}\text { Torque } \\
(N \times m)\end{array}$ & Efficiency & $\begin{array}{c}\text { Substitution } \\
\text { percentage } \\
x(\%)\end{array}$ & $S F$ \\
\hline \multirow{3}{*}{$T_{e j}$} & $\eta_{\mathrm{i} 1}$ & 0 & 1 \\
\cline { 2 - 4 } & $\eta_{\mathrm{i} 2}$ & $x_{\mathrm{i} 2}$ & $S F_{1}$ \\
\cline { 2 - 4 } & $\eta_{\mathrm{ia}}$ & $x_{\mathrm{ia}}$ & $S F_{2}$ \\
\cline { 2 - 4 } & $\eta_{\mathrm{ik}}$ & $x_{\mathrm{ik}}$ & $S F_{k}$ \\
\hline
\end{tabular}

A scale factor which shows the deviation of the efficiency at a particular substitution percentage from the base line efficiency is proposed. The base line is the efficiency for pure Diesel operation $(x=0 \%)$, the result obtained in the present work. A regression may be made in order to obtain the scale factor $S F$ as a function of torque, engine speed and substitution percentage:

$$
S F=S F\left(T_{\theta^{v}} n_{s} x\right)
$$

Larger the number of known operation points, better the approximation obtained by the regression. Finally, the efficiency can be scaled for each operation point and the efficiency can be shown as a function of torque, speed and substitution percentage:

$$
\eta=\eta\left(T_{e^{x}} n_{s} x\right) \text {. }
$$

\section{Recommendations}

Experimental tests must be carried out in order to get real information about the Diesel engine operation points. For future researches experimental data is also needed for modeling Diesel-natural gas dual operation behavior. Besides, it is important to classify Diesel engines according to their constructive characteristics before applying models.

\section{References}

[1] Bedoya ID, Arrieta AA, Cadavid FJ, Pareja JA. Efecto del grado de carga y la cantidad del combustible piloto en el comportamiento mecánico ambiental de un motor dual diesel-biogás para generación de electricidad. Universidad de Antioquia. 2007.

[2] Tschöke H, Heinze $H$. Einige unkonventionelle Betrachtungen zum Kraftstoffverbrauch von PKW. Magdeburger Wissenschaftsjournal. 2001.

[3] Sahoo BB, Sahoo N, Saha UK. Effect of engine parameters and type of gaseous fuel on the performance of dual-fuel gas diesel engines-A critical review. Renewable and Sustainable Energy Reviews 2009.

[4] ASAE EP496.2 Agricultural Machinery Management. American Society of Agricultural Engineers. 2003.

[5] Grisso RD, Kocher MF, Vaughan DH. Predicting Tractor Fuel Consumption. Biological Systems Engineering: Papers and Publications. University of Nebraska 2004.

[6] Popescu S, Dumitru I, Boruz S, Kiernicki Z. Elaboration the mathematical models to obtain the optimum performace of the agricultural tractor engine. TEKA Kom. Mot. Energ. Roln. 2006, 6, 117-122.

[7] Durković R, Damjanović M. Regression models of specific fuel consumption curves and characteristics of economic operation of internal combustion engines. Facta Universitatis Series: Mechanical Engineering Vol. 4, No 1, 2006, pp. 17 26.

[8] Agudelo J. Estudio de motores en estado transitorio. Universidad de Antioquia, Colombia. 1998 